\title{
DECLARADO EN SECRETO. MATRIMONIO CLANDESTINO Y CONSENTIMIENTO PATERNO EN LA BARCELONA PRETRIDENTINA*
}

\author{
POR \\ MARIELA FARgAS PEÑARROCHA ${ }^{1}$ \\ Universidad de Barcelona
}

\section{RESUMEN}

Sabemos muy poco sobre las experiencias de matrimonio clandestino en la Barcelona de principios de la época moderna. Pero aún sabemos menos acerca del papel que tuvo el consentimiento paterno. Lejos de controlar aquellas uniones, las estimuló. Porque la familia también lo usó como instrumento regulador del sistema de conflicto y consenso en el seno de matrimonios y linajes. En este texto analizamos una microhistoria que muestra un asunto desconocido: cómo la ambigüedad del discurso sobre la participación de padres y de madres en el consentimiento matrimonial de las hijas pudo dar cauce a la clandestinidad.

PALABRAS CLAVE: matrimonio clandestino; consentimiento paterno; familia; género; Edad Moderna.

\section{SECRETLY DECLARED. CLANDESTINE MARRIAGE AND PATERNAL CONSENT IN BARCELONA BEFORE THE COUNCIL OF TRENTO}

\begin{abstract}
We know very little about clandestine marriage in early modern Barcelona. We know less about the role that parental consent had in these unions. He encouraged it because the family's pressure ended in disobedience and the family also used it according to their convenience. Now we research a casuistry on an unknown matter: how the ambiguity of the normative discourse regarding the participation of father and mother together, to give their consent, could finish up in clandestinity.

KEY WORDS: clandestine marriage; paternal consent; family; gender; Early Modern History.
\end{abstract}

CÓMO CITAR ESTE ARTículo / CiTATION: Fargas Peñarrocha, Mariela. 2021. «Declarado en secreto. Matrimonio clandestino y consentimiento paterno en la Barcelona pretridentina». Hispania Sacra LXXIII, 148: 419-430. https://doi.org/10.3989/hs.2021.032

$\begin{array}{ll}\text { Recibido/Received } & 13-04-2020 \\ \text { Aceptado/Accepted } & 13-07-2020\end{array}$

\section{ENCRUCIJADA SOCIAL DEL MATRIMONIO CLANDESTINO}

Constituye un asunto afianzado entre los estudios históricos el considerable acomodo que gozó el matrimonio clandestino, desde los inicios de la Edad Media hasta los tiempos modernos. Una práctica arraigada entre otras tantas costumbres familiares y ritos paganos inspirados en una noción comunitaria de intercambio y vinculados a la supervivencia de las estructuras de parentesco forjadas durante el largo medievo. Cuestiones tales ya fueron destacadas por la antropología de inicios del siglo XX. ${ }^{2}$ Esta disciplina, cen-

* Con proyecto financiado: PID2019-103970GB-I00.

1 marielafargas@ub.edu / ORCID iD: https://orcid.org/00000003-4352-8457

2 Una síntesis en Casey 1990, 107. trada entonces en el análisis del funcionamiento de sociedades no desarrolladas, iba a sentar las bases de los posteriores monumentos de síntesis sobre la historia de la familia y del matrimonio, por Jean Louis Flandrin, Georges Duby, Jack Goody, Philippe Ariès, Lawrence Stone y James Casey, principalmente. ${ }^{3}$ De la perdurabilidad de las viejas y heterogéneas prácticas matrimoniales más allá de la Edad Media, tendrían también mucho que ver algunos elementos de la civilización romana. Roma había tolerado la coexistencia de un abigarrado elenco de usos, según lugares y grupos sociales. En ese contexto iba a irrumpir la observancia del ma-

\footnotetext{
3 Flandrin 1984; Duby 1985; Goody 1986; Ariès 1988; Stone 1990; Casey 1990.
} 
trimonio cristiano. ${ }^{4}$ Un misterio sacramental, así designado desde el siglo IV, y sujeto a nuevas prescripciones morales cuya predicación desconcertaría en la praxis tradicional de muchas familias, que optaban por adaptar aquel a sus necesidades. Es posible pensar que esos ajustes constituyesen directamente una forma de entender un patrón de realización del matrimonio que resultaba complejo. En efecto, el matrimonio como acto jurídico, que la Iglesia adoptaba del romano, contemplaba un recorrido de tres etapas. El derecho justinianeo las designaba como coniugium, nuptiae y matrimonium. Las fronteras entre dichas fases no estaban claras, se percibían de formas distintas, se consensuaban. ${ }^{5}$

Por lo menos así se haría mientras el poder secular mantuviese la jurisdicción sobre este asunto, hasta los siglos IX-X, cuando la Iglesia lograba al fin el monopolio en dicha materia. La obra de Adhémar Esmein es aún hoy la más completa sobre la historia del matrimonio desde el derecho canónico y nos describe con detalle el lento proceso de ensambladura del nuevo modelo y de sus reglas, entre las que la potestad disciplinaria fue la primera en llevar a cabo su labor. Incluso en el momento en que la Iglesia asumiera el control definitivo de la legislación matrimonial, aún permanecerían ciertos elementos de la ley secular romana. ${ }^{6}$ La noción de sacramentalidad ajustada al derecho divino, con consecuencias jurídicas como la indisolubilidad, vino a aumentar la confusión. El fundamento matrimonial del consenso permanente romano, a cuyo defecto se disolvía la unión, se modificaba para dar paso al consenso inicial, que daba lugar a un nuevo estado. ${ }^{7}$ Pensemos en los tiempos de eclosión de aquellos clanes feudales cuyos jefes enviaban a sus hijas a contraer matrimonios exogámicos destinados a fortalecer el sistema de protección, pero que por otro lado no gozaban de garantías para aquellas. En este clima, la indisolubilidad tropezaba con la prioridad de asegurar el tronco común con descendencia. ${ }^{8}$ Y así, durante mucho tiempo, las comunidades dieron rienda suelta a sus costumbres para establecerse y perpetuar la familia.

Las inercias locales y las prácticas ya conocidas revelaban la clandestinidad matrimonial como una opción. En modo alguno se concebía tan solo como resistencia frente a la patria potestas, por cierto en auge en el siglo XII cuando el matrimonio se desarrollase como un concierto entre linajes agnaticios y la sustitución del precio de la novia por la dote fortaleciese la dependencia paterno-filial. ${ }^{9}$ Su dilatada existencia a lo largo de los siglos, la viabilidad del hábito clandestino, se antoja pues compleja y obedece a numerosos factores de orden social y cultural: desde la consideración de la promesa de matrimonio intercambiada entre hombre y mujer como una auténtica prueba de voluntad, seguida de su consumación; la fuga de la pareja y posterior matrimonio oculto en contra de los propósitos familiares, contra la autoridad del pater familia o del jefe del clan, cuya intervención no en vano se aceptaba en tanto el control de tales uniones suponía la estabilidad de la propiedad y el res-

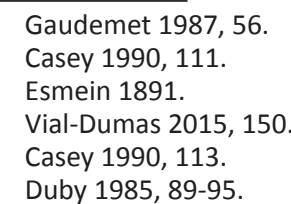

peto a las reglas de su transmisión; ${ }^{10}$ el rapto de la doncella ${ }^{11}$ y la celebración de esponsales y matrimonio secreto, en el marco de la guerra feudal, táctica empleada para forzar ulteriores acuerdos sobre límites territoriales. ${ }^{12}$ En este sentido no fue inusual la concurrencia de una parte de la familia en la urdimbre de un matrimonio clandestino, - por medio del secuestro y depósito de la joven por el padre o tutor, también para evitar el rapto del pretendiente-, cuando estallaban graves discrepancias en la elección del cónyuge, respecto al parecer de otra parte poderosa de la familia. En tales casos, cuando tenían lugar entre nobles, incluso la joven monarquía renacentista apoyaría la alternativa secreta, en la convicción de que se evitarían con ella enfrentamientos más graves en el seno de las grandes familias. Susceptibles de enredar en sus asuntos a sus redes de clientes y deudos, asuntos tales podían degenerar en guerra feudal contraria a los intereses de estabilidad y control territorial del incipiente estado moderno. ${ }^{13} \mathrm{~A}$ esta situación obedece la historia acaecida en la noble familia Gralla, que tuvo lugar en la Barcelona de los años cincuenta del siglo XVI y sobre la que volveremos más adelante: quien entonces ostentaba el ilustre cargo de maestre racional, Francesc de Gralla, al discrepar con su esposa acerca de los futuros cónyuges de sus hijas, decidió secuestrarlas y preparar clandestinamente sus matrimonios. ${ }^{14}$

Resulta evidente la indolencia instaurada respecto a las reglas de realización del matrimonio cristiano. Casos análogos se sucedían una y otra vez. Y las calamidades que conllevaban también; la Iglesia advertía de riesgo de bigamia, adulterio, concubinato y abandono de mujeres, como consecuencia de la clandestinidad matrimonial. ${ }^{15}$ Jean Gaudemet notó cómo el recelo por evitarla queda documentado ya en los primeros tiempos del cristianismo: se observa en el siglo IV, en la colección del Concilio de Laodicea, más tarde en los escritos de san Ambrosio y de san Agustín. ${ }^{16}$ Los concilios provinciales del medievo no cesaron de insistir: por mencionar aquellos de nuestro espacio de estudio, el de Tarragona del año 1129 declaraba ilegales las uniones clandestinas. ${ }^{17}$ Pero la interpretación eclesial sobre el carácter consensual del matrimonio siguió albergando varias opciones en la vida real, más relajadas, que debilitaron este empeño. ${ }^{18}$ Una abundante producción canonista estuvo apercibiendo durante toda la Baja Edad Media sobre los muchos caminos que llevaban al matrimonio clandestino: la unión contratada ocultamente y sin la presencia de ningún testigo que, por lo tanto, no podía ser probada judicialmente; la que sí se lograba probar, pero no estaba acompañada de solemnidad alguna como la bendición de un sacerdote; y la

10 Casey 1990, 109. Este autor trabajó las fórmulas del rapto o el «sacar a la novia» en el marco de la archidiócesis de Granada para e período moderno.

11 Algunas mujeres los utilizaban para encubrir una deshonra, Dyer 2003; Quesada 2018

12 Charageatu 2014; Dunn 2013, 82-98.

13 D’Avray Papacy 2015, 168 y ss.

14 Archivo Histórico de Protocolos de Barcelona, Francesc Sunyer, Primus liber testamentorum, testamento de Guiomar de Hostalrich, 1555, leg. 20, ff. 143r-144v.

15 Joyce 1948, 108.

16 Gaudemet 1987, 62.

17 Kamen 1998.

18 Aznar Gil 2006 
unión ajena a la exigencia de publicidad dictada, al fin, en el IV Concilio de Letrán de 1215 , el primer punto y aparte en la historia del matrimonio, cuando la clandestinidad pasaba a ser denunciada como un gravísimo problema. ${ }^{19}$

No es posible desvincular este cambio de otros que operaron con carácter previo. J. Goody y J. Casey nos recuerdan cómo la introducción de la dote de la novia en el área mediterránea desde el siglo XI, a lo que contribuiría la recuperación del derecho romano, fue fundamental en la transformación del matrimonio. La dote implicaba la transmisión de bienes de una familia a otra. Debía acompañarse de cooperación y lealtad entre ambas. ${ }^{20}$ Se trataba de un acuerdo económico bilateral tanto más respetado cuanta mayor fuera su publicidad. Proteger la dote de la mujer requería proteger la forma del matrimonio y controlar la capacidad de elección femenina. El matrimonio no podía concebirse entre desiguales. Paralelamente, fueron asentándose los privilegios de exclusión, en torno al derecho de primogenitura con preferencia por la masculinidad. La posición preeminente del heredero varón dentro de su linaje, el hermano de la novia, se convenía sobre la larga tradición de poder del pater familia. Ya no solo el padre, sino también el hermano tras fallecer aquel, decidían el matrimonio de la hermana. La legislación secular, atenta a las súplicas de unas clases privilegiadas deseosas de conservar los patrimonios establecidos tras su revolución feudal, no podía permanecer al margen. Las concomitancias entre legislaciones son evidentes. ${ }^{21}$ Para el caso catalán un Usatge del siglo XI recogía el derecho de los padres a desheredar si las fillas nos volran ajustar a marits. Las Constitucions de sposalles y matrimoni, en su título I, manifestaban idéntica voluntad de regulación y prohibición. Así, las cortes de Barcelona del año 1413, estatuían por capítol de cort la siguiente prescripción: Com fer e contraure esposalles o matrimonis amagats e seduir e enganar las doncellas fillas de algu per aytal causa o esguart, sia cosa molt temerària, injuriosa, greu, e sens reparació e prohibida pels nostres predecessors molts illustres per ço seguint los vestestigis lloables de aquells, ab la present, de aprobbatio, e consentiment de la Cort prohibim e reprobam esser fetes sposalles e matrimoni amagats. En la misma norma se insistía que: matrimoni ab alguna donzella o verge sens voluntat o consentiment pare de aquella si vivia e sil pare no del avi paternal e mare de aquella haura e si avi e mare no haura

19 Esmein 1891, I: 182

20 Casey 1990, 117

21 Así, por ejemplo, en Castilla, el Fuero real ordenaba: que todos los casamientos se fagan por aquellas palabras que manda Sancta Eglesia (...); e todo casamiento fágasse conçegeramiente non a furton (...); e qui a furto fizierre casamiento, peche C morabedís al rey, e si los non ouiere, todo lo que ouiere sea del rey, e por lo que fincare, sea el cuerpo a merçet del rey. Y las coetáneas Partidas recogen el contenido de las Decretales: "este encubrimiento cae a las vezes en fecho de los desposorios, e de los casamientos, por ende defendio santa eglesia que lo non fiziessen. Lo vno porque es sacramento...». En 1505, la ley 49 de Toro alertaba de nuevo: el que contragere matrimonio que la Iglesia tuviere por clandestino con alguna muger, por el mismo hecho el y los que en ello intervinieren, y los que de tal matrimonio fueren testigos incurran en perdimiento de todos sus bienes (...) y sean desterrados destos nuestros reynos, en los quales no entren sopena de muerte: $y$ que esta sea justa causa para que el padre, y la madre puedan desheredar si quisieren á sus hijos o hijas que el tal matrimonio contraxeren: lo qual otro ninguno no pueda acusar sino el padre, y la madre, muerto el padre. Bermejo 2009, 145. del tudor de aquella ab la vn dells sino lo tudor, ab dos o tres dels pus acostats parents de la dita donzella o fadrina, fino haura tudor, els dits pus dos o tres parents de aquella, o coneixerà carnalment o sen manara o rapara violentment, o de son grat, per esguart, o causa de ser o contraure ab ella spofalles matrimoni o ab promissio a la dita o fadrina o a altre per ella de fer contraure ab ella matrimoni o sposalles, ipso facto de pena de exili perpetual () e encara de pena de mort natural si rapte o altre acte violent hi entrevengut (...) si doncs la dita donzella o o lo pare e mare de aquella no volran de usar la provisio del Usatge de Barcelona comença Siqui Virginem ço es que haver o pendre per marit aquell qui violentament la haura corrompuda, com en cas volem que cessen las penas sobreditas, e la dita donzella o fadrina que a les dites sposalles, o matrimoni amagat, o al dit rapte, o menament, haurà consentit, de tots bens a ella pertanyents, o sperant pertànyer en la heretat, o bens de son pare, o mare, e de quiscu de ells, per raho de la legitima o en altra qualsevol manera, sie ipso facto privada (...) e lo testimoni o testimonis que seran, o diran, si esser entrevinguts scientment en tals sposalles, o matrimonis amagats, $e$ reprovats, sien semblantment punits de pena de semblant exili. Dos siglos más tarde, en las cortes de Monzón de 1537, Carlos V aprobaba un nuevo capítol de cort ordenando: que dita constitució (la precedente) sie entesa encara que noy entrevinga rapte, o altra violentia, ajustant a la dita constitució que si lo qui pretendrà haver casat ab alguna donzella, o viuda, desafiara, o desafiar farà lo pare, o mare, o parents, o tudors, o curadors de las dites donzelles, o viudes, per causa de dit matrimoni, que aquell tal qui desafiara, o desafiar fara, o los qui per ells lo faran, sien haguts ipso facto gitats de Pau y Treva..$^{22}$ Hay que señalar la nitidez de la disposición al definir la clandestinidad matrimonial siempre en relación a la mujer. Estaban en juego la honra femenina y la heteroestima de la familia. ${ }^{23}$ Los antropólogos encontraron un nexo entre los valores mediterráneos del honor masculino o la vergüenza femenina, presentes desde la más pretérita civilización occidental y el matrimonio secreto. Éste último se había llegado a convertir en un ritual aceptado por las comunidades para dejar a salvo aquellos intereses, fingiendo una situación de emergencia cuando se ponía en riesgo la posición pública de riqueza o de linaje. ${ }^{24}$ También durante el medievo, en algunos pueblos de tradición germánica, el rapto y subsiguiente unión clandestina constituían una fase previa al matrimonio admitido. ${ }^{25}$

En la citada normativa es obvia la evolución del recrudecimiento de la pena, sin duda tras revelarse estériles los esfuerzos precedentes. No es siquiera infundado pensar que la clandestinidad fuera en aumento entre la Baja Edad Media y la Edad Moderna. Varios indicios, que explican la evolución de las élites, permiten sospecharlo. Hay que recordar que en ese tiempo confluyen dos procesos de tipo social y político, el acortesanamiento o la urbanización de la nobleza, y el ascenso de la burguesía. Unos y otros pujan

22 Constitutions y altres drets de Catalunya compilats en virtut del Capitol de Cort LXXXII de las Corts per la S. C. y R. Majestat del rey don Philip IV, Barcelona, Col·legi de I'Advocacia de Barcelona, 1704, 352-354.

23 Candau 2014, 14-25; Pérez Molina 1997, 30-33.

24 Casey 1990,100 y ss.

25 López Medina 2013, 15. 
por servir al rey, compiten por los cargos de la corte, mientras consolidan o inician su condición como clase rentista y señorial. La competencia es tan intensa, en toda la Europa urbana de la época, que se reflejará en la concertación de matrimonios mixtos, en el progresivo intervencionismo de las familias y en la desbocada inflación de las dotes femeninas como anzuelo destinado a captar a los más ricos, influyentes y bien relacionados pretendientes. Una suma de resortes necesarios para lograr las mejores alianzas, proseguir las carreras ascendentes, ennoblecerse. En este punto, es donde se ubicaría un aumento de la clandestinidad al menos en dichos grupos: por parte de las hijas, contradiciendo las decisiones de sus familias, fuertemente condicionadas por el deseo de nuevas oportunidades de poder, o por la necesidad de conservar; por parte de las propias familias, utilizando el secuestro y posterior matrimonio secreto de aquellas, como demostración de fuerza en el marco de linajes polarizados internamente por la diferenciación social surgida de la primogenitura y la exclusión hereditaria. Cronológicamente se sitúa este proceso en los albores de la modernidad. Aún quedaba mucho para asistir a la disolución del sistema de linaje abierto ${ }^{26}$ y la instauración del mundo doméstico de las familias nucleares. Es muy posible también que tales conductas encubrieran otras intenciones, como renegociar la inflación dotal, que entre los privilegiados se advertía tan elevada como inviable. ${ }^{27}$

Pese a la relevancia del tema aún faltan estudios que desde una metodología comparativa, entre sistemas legales, entre grupos sociales, permitan comprender mejor la multicausalidad del problema. Para la Barcelona moderna el desconocimiento es aún mayor, salvo en lo concerniente al siglo XVIII que ha estudiado Marie Costa. Por otro lado Henry Kamen nos ha provisto de algunos datos que explican el arraigo del fenómeno en la Cataluña rural post-tridentina. ${ }^{28}$ Más allá de estos confines, hoy la historiografía social está centrándose en la intervención de las mujeres. ${ }^{29}$ Parece que algunas optaron por el secreto, no tanto para huir y doblegar a su entorno, sino como reclamación de un rol más activo en la toma de decisiones familiares. ${ }^{30}$ También se ha dicho que estas uniones informales, al incurrir en dudas de validez, proporcionarían una mayor libertad para aquellas parejas que no deseasen sujetarse por mucho tiempo, en un contexto que no consideraba el divorcio. ${ }^{31}$ Por otro lado, si la dote se componía primordialmente de la propiedad de la rama materna, como apuntaba G. Duby para el período bajomedieval, siendo sus bienes ajenos al patrimonio principal del linaje reservado al heredero primogénito, las mujeres pudieron ejercer mediante el matrimonio clandestino una suerte de autodeterminación, liberadas de las obligaciones que recaían en sus hermanos. Esta noción, con todo, no se adecúa a otras interpretaciones. Así, siguiendo a J. Casey, a medida que penetramos en la era moderna, la dote no representa solo un capítulo más del sistema de exclusión, sino un auténtico compromiso financiero con el destino de

\footnotetext{
26 Stone 1990.

27 Fargas 1997, 132-146.

Costa 2007; Kamen 1998; Gascón 2013

Finch 1990; Wall 1995.

Hacke 2001

Armstrong-Partida 2017; Byars 2018.
}

la hija que se casa. ${ }^{32}$ En un entorno de hijas con posibilidad de ser dotadas, la clandestinidad se descubre en su versión más desafiante. Las comedias del Barroco, muy populares, representaron en múltiples ocasiones a damas y plebeyas organizando secretamente estos matrimonios. ${ }^{33}$ Silvana Seidel nos relata la existencia de un auténtico desenfreno clandestino, con matrimonios celebrados en balcones y ventanas en penumbra, en establos, en posadas, en bosques. ${ }^{34}$ Tan clandestinas como estos eran las uniones realizadas en fiestas, en tabernas o mesones, como desenlace de juegos o apuestas. ${ }^{35}$ La casuística es inagotable y alcanzaba a los ritos. Cecilia Cristellón explica que en Venecia se presidían por el padre, por la madre, o por el confesor. ${ }^{36}$ Es interesante recoger, a título de ejemplo, cómo la Partidas de Alfonso $X$ en el siglo XIII, ya tipificaron parte de esta heterogeneidad: La primera es cundo los fazen encubiertamente e sin testigos, de guisa que non puedan provar. La segunda es quando los fazen ante algunos mas non demandan la nouia a su padre, o a su madre, o a los parientes que la han en guarda, nin le dan sus arras ante ellos, nin les fazen las otras onrras que manda santa Eglesia. La tercera es quando non lo fazen saber concejeramente en aquella Eglesia onde son perroquianos. ${ }^{37}$

La historiografía está de acuerdo en que la distinción del derecho canónico entre la promesa de casarse en el futuro y casarse en el presente no encontraba su lugar en la mentalidad de las gentes de la época. Lloyd Bonfield ha explicado que al concebirse la unión matrimonial como proceso y no como acto único, se incrementó el papel de la comunidad que escapaba al control de la ley. ${ }^{38}$ Trabajos sobre rituales muestran a campesinos y a clases propietarias negociando el capítulo económico, permitiendo sucesivos encuentros entre los prometidos, intercambiando regalos, decidiendo acerca de las celebraciones de los esponsales y del intercambio de palabra en la Iglesia. ${ }^{39}$ Para la Andalucía moderna existen hoy estudios imprescindibles llevados a cabo por María Luisa Candau y bajo su dirección. Esta autora nos ha proporcionado análisis de casos a partir del uso de fuentes procesales. La memoria colectiva permitía acogerse a una tradición que primaba el consentimiento mutuo, aun a escondidas. A su lado toda una red de apoyos, testigos y encubridores, contribuyeron a la expansión de la clandestinidad matrimonial..$^{40} \mathrm{El}$ rol de las familias, ha insistido Lorenzo Pinar, fue decisivo. ${ }^{41}$ Y siempre la palabra dada, reclamada en los tribunales de justicia, como conoce Margarita Torremocha. ${ }^{42}$ También los sistemas de herencia, o las modalidades del hábitat que en España contrastaban norte y sur, condicionaban las encrucijadas de la clandestinidad matrimonial y su resolución social y legal, recogiendo un estudio de Ofelia Rey. ${ }^{43} Y$ aquella suerte de licencia de los padres,

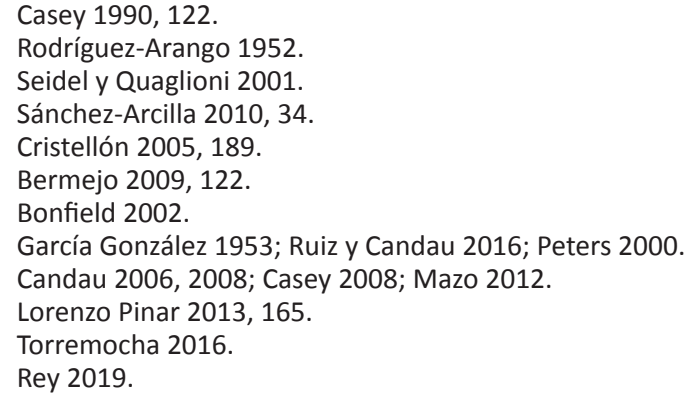


ratificada una y otra vez al menos hasta el Concilio de Trento. A la coacción seguía el desacato. Moralistas y juristas insistían en atender a la opinión de los padres dando forma a una larga tradición jurídica que desembocaba en penas de separación de la herencia para las hijas en todos los derechos territoriales. ${ }^{44}$ El matrimonio concertado era la lógica del asentamiento feudal y el desarrollo de las ciudades. ${ }^{45} \mathrm{La}$ doctrina de los doctores no dejó de lado este asunto. Joan Pere Fontanella, autor en el siglo XVII de la mayor obra jamás escrita sobre los pactos matrimoniales catalanes, señalaba la validez de las disposiciones testamentarias puestas por los padres que prohibían contraer matrimonio con una determinada persona. ${ }^{46}$

La judicialización del suceso clandestino permite conocer sus notas comunes, sus experiencias, si bien se escapan las circunstancias de las que fueron resueltas privadamente y dejaron menor huella documental. Jutta Sperling ha trabajado una muestra de causas seguidas ante los tribunales eclesiásticos castellanos en 1564. De su investigación se recoge que un elevado $68 \%$ partieron de una denuncia de clandestinidad. Se trata de una cifra similar a las de otros países mediterráneos con régimen de igualdad hereditaria. ${ }^{47} \mathrm{R}$. B. Outhwaite ha demostrado igualmente la fuerte presencia de la clandestinidad en Inglaterra, antes y después de la Reforma, ${ }^{48}$ como sucedería en la Alemania luterana, donde los primeros reformadores, al definir el matrimonio como vocación seglar, subrayaron el error del matrimonio clandestino. El celo de los puritanos exigió la sumisión de la sociedad laica a unos férreos valores de conducta moral que contradecían aquel y daban preponderancia al papel del patriarca. ${ }^{49}$ La intervención paterna estaba justificada por la inversión material y moral que hacía sobre sus hijos. ${ }^{50}$ Los tribunales protestantes se ponían del lado de los padres. Su actividad, con todo, demuestra una lenta erradicación. ${ }^{51}$ En este texto nos vamos a centrar en el periodo previo a las grandes decisiones al respecto del Concilio de Trento. Un tiempo de enorme diversidad de hábitos como se ha señalado y que tuvo su reflejo en las discrepancias del debate doctrinal, en la laxitud de la censura. ${ }^{52}$ Y tras este preludio, es momento ya de indicar que partimos del planteamiento que el matrimonio clandestino contó con infinidad de cauces legales o paralegales, sociales y culturales, para su expansión. En ese marco, nuestra hipótesis pretende demostrar que el consentimiento paterno, capacitado para funcionar como freno a aquel, ocasionó sin embargo tensiones entre quienes podían intervenir o no en él, tensiones por los límites de su aplicación. Estas tesituras de conflicto doméstico y familiar, muestra de resquicios fuera de control en el ámbito de la familia patriarcal, iban a ser aprovechadas tanto por los hijos como por los padres para urdir un matrimonio clandestino. Comprenderlo, nos introduce en el funcionamiento familiar.

44 Bermejo 2009, 140

45 Casey 1990, 125.

46 Maspons 1952, 134-135.

47 Sperling 2004.

48 Outhwaite 1995, ha clasificado el matrimonio clandestino en varios tipos: a) sin sacerdote ni en la iglesia, b) con sacerdote pero no en la iglesia, c) sin bandos ni licencia, d) en iglesias no registradas en territorio reformado, e) en prisión. Ver también Newton 2014.

49 Watt 2004, 205-249.

50 Bonfield 2002

51 Ozment 1988, 40-44; Korpiola 2011.

52 Acerca de la litigiosidad, Donahue 2007.

\section{DOCTRINA Y MORAL DEL CONSENTIMIENTO Y EL MATRIMONIO CLANDESTINO}

En las líneas que siguen se hace imprescindible abordar las claves de la compleja noción de consentimiento. En su doble acepción, el que partía de los cónyuges y el que provenía de la familia. Antagónicos ambos, pero interrelacionados, resultan esenciales para comprender el devenir de esta modalidad de matrimonio. El consentimiento paterno, como hemos sugerido, pudo hacer de agente de la clandestinidad matrimonial. Si esta buscaba doblegar la autoridad de la casa, aquel también podía usar y abusar del matrimonio clandestino. $Y$ principalmente porque los términos de la prestación de ese consentimiento se acogían de formas diversas. ${ }^{53}$ Si por un lado la Iglesia desde el siglo XII estaba apoyando la libertad de elección de los cónyuges, por otro consideraba que por derecho divino era oportuno que los jóvenes recabasen la aprobación de los padres basándose en la honra debida. ${ }^{54}$ Nadie mejor que ellos para proteger a sus hijas. ${ }^{55} \mathrm{Y}$ principalmente a ellas, sujetas al padre, o a los hermanos a falta de aquel. Mas las limitaciones del discurso avivaban la transgresión: incluso quienes penalizaron la omisión del consentimiento paterno, seguían validando la unión clandestina. La conciliación justa entre la autoridad paterna y la libertad fue siempre difícil. Como señala José María Laina en esa contienda la familia pesó con fuerza para interpretar las normas. ${ }^{56} \mathrm{Y}$ es que la penetración social y cultural del consentimiento paterno era tal, que si los hijos lo requerían, también la propia familia lo necesitaba tácitamente de su propia comunidad, de su red de parentesco, por criterios de integración social, para satisfacer las reglas de convivencia. ${ }^{57} \mathrm{Y}$ no hay que olvidar que la Iglesia arrastraría mucho tiempo su acomodo a la legislación romana en lo relativo al consentimiento paterno, ininteligible fuera de la figura del pater familia quien asumiera en exclusiva la patria potestas..$^{58}$ Casar a los hijos constituía ahora un deber de los padres cristianos. De ambos. Vial-Lumas nos recuerda, partiendo de Health Dillard, que en los primeros siglos del cristianismo se empieza a valorar la participación de la madre en el consentimiento, por encima del resto de parientes. ${ }^{59}$ Cada uno ejercía de representante de sus propias familias. Un pariente de la madre tenía potestad para introducir objeciones y su mediadora era ella, que intentaría cambiar la opinión del esposo. ${ }^{60}$ Estas situaciones se dieron en muchas localidades castellanas que se apartaron de la ley visigoda. Y es que el Fuero juzgo, en el siglo VII, reconocía el derecho de aquella a emitir su consentimiento pero bajo condición de viudedad y permaneciendo sin casarse. Sin embargo será el Fuero real de Alfonso X, quinientos años después, el primero que hace indispensable el consentimiento no tan solo del padre, sino de la madre, al menos hasta los treinta años de edad de la hija, para así poder disfrutar de la herencia de los dos. ${ }^{61}$ En Barcelona un capitol de cort de 1218 ordenaba

\footnotetext{
53 Aznar Gil 1995; Gibert 1947; Iglesia Ferreirós 1974

54 Morales y Alonso 1895, II: 33.

Vial-Dumas 2015, 152

Laina 1992, 23.

Blanco Carrasco 2016, 111.

Usunáriz 2005, 169.

Vial-Lumas 2015; Gaudemet 1987, 1; Finch 1990.

Dillard 1993, 62.

Ayllón 1862, 12
} 
a las hijas tomar esposo con confentiment expres Pare o de Mare o de Tudors o defallents fens confentiment dels proifmes. Aquí las madres intervenían en el caso que el primero, el padre, no pudiera hacerlo. A semejante conclusión se llega tomando otro capítol de cort de 1413 que penalizaba los esponsales y los matrimonios secretos sin consentimiento del Pare de aquella fi vivia e fil Pare no vivia del Avi Paternal e Mare de aquella fin haura e fi Avi e Mare no haura del tudor de aquella ab la vn dells fino lo dit Tudor ab dos o tres dels pus acoftats Parents de la dita Donzella o Fadrina e fino haura Tudor dels dits pus acoftats dos o tres Parents de aquella. ${ }^{62}$

Lyndal Roper ha escrito que el consentimiento paterno se encontraba en las entrañas de lo que se entendía por matrimonio, en el que primaba la relación social, ${ }^{63}$ lejos del absurdo de las pasiones y la sinrazón de los jóvenes, como señalarían Erasmo y otros eruditos. Juan Luis Vives aún añadía que la doncella no debe hablar cuando sus padres entienden en su casamiento. ${ }^{64}$ Hasta las discusiones sobre el asunto durante las últimas sesiones del Concilio de Trento enfrentaron a partidarios de la autorización familiar contra quienes subrayaban la libertad de los cónyuges. ${ }^{65} \mathrm{El}$ consentimiento de fuero interno no cabe duda que daba vía libre a las uniones clandestinas suscitando gran temor entre las familias, especialmente entre las clases propietarias. Pero, por otro lado, el consentimiento paterno, el mismo llamado a priori a mantener la paz de la casa ${ }^{66}$ o el buen nombre del linaje, también usó cuantos instrumentos tenía a su alcance para aprovechar la oportunidad del casamiento de sus hijas, y convertirla en un triunfo en el juego de la competitividad contra otros grupos u otras ramas del tronco familiar o incluso para ajustar un acuerdo en el mismo. Uno de esos instrumentos fue el matrimonio clandestino. Claro que en tal caso ya no se trataba de una unión que alarmase a los miembros del hogar. Podía camuflarse bajo la apariencia de una solicitud de depósito dirigida a las autoridades eclesiásticas para la hija casadera. Marta Ruiz ha estudiado cómo el riesgo que ocasionaba la defensa de la libertad de consentimiento, en situaciones de conflicto, se atenuaba mediante el resguardo de la novia en depósito. ${ }^{67}$

La defensa y práctica del consentimiento paterno debió incrementarse a medida que la Iglesia proclamaba con firmeza la legitimidad tanto de los matrimonios fórum internum como fórum externum. Esmein reconoce que la convicción por el solo consenso en derecho canónico, heredado de la tradición romana, facilitó las prácticas de siempre. ${ }^{68} Y$ mantuvo latentes sustanciales ambigüedades, acerca de si el consenso tenía lugar con los sponsalia per verba de futuro, que tenían efectos jurídicos, o en una fase posterior. Algunos canonistas encontraron razonable distinguir entre promesa simple y promesa jurada. Pero, para Graciano, si en ese tiempo intervenía copula carnalis nacía matrimonio verdadero. Pedro Lombardo introdujo en consecuencia el

62 Constitucions i altres drets. Titol I. De esposalles i matrimonis. Josep Llopis, Juan Pablo Martí En casa de Joan Pau Marti y Joseph Llopis estampers, 1704.

63 Roper 1985, 98; Hanley 2003; Diefendorf 1996.

64 Telle 1954, 205-231.

65 Christensen-Nugues 2014

66 Orlandis 1944

67 Ruiz Sastre 2016.

68 Esmein 1891, I: 63-94; Weigand 1990. consensus de praesenti, que concedía al consentimiento una voluntad actual. ${ }^{69}$ Pese a este avance, aún la promesa podía entenderse cual matrimonium initiatum, ${ }^{70}$ por ello la modalidad clandestina, que constituía un contrato, era válida. En el mismo siglo XII iba a ser relevante una decretal de Alejandro III, que insistiría que con las palabras de futuro simultáneamente consumadas se prohibía contraer una segunda unión. El final de su pontificado asiste a la conjugación de las tesis de Graciano y de Lombardo, produciendo una nueva doctrina de dualidad de modos de formación del vínculo matrimonial. Las palabras de presente constituían matrimonium ratum, pero las palabras de futuro seguidas de la unión carnal constituían matrimonium ratum y consummatum y por ello indisoluble. No eran escasos los vaivenes que experimentaba la doctrina canónica. Como señala Sánchez-Arcilla, obedecían a la fuerza de las costumbres locales. ${ }^{71}$ No ignoraba la Iglesia, con todo, además de los problemas de inseguridad jurídica, los riesgos morales a que conducía la primacía del consenso con ausencia de formalidades. Así, por medio de cánones conciliares, sínodos provinciales y decretales, no cesó de recomendar su ritualización, no obstante la diversidad de fórmulas, preteriendo y penalizando la clandestinidad, mas sin especificar qué se debía entender por tal. ${ }^{72} \mathrm{~A}$ su lado, el problema de la prueba, confiada a los propios actores, a los testigos y confidentes, al gesto del lucimiento de un anillo, a la adopción de un nuevo nombre, comprometía los efectos del consentimiento. ${ }^{73}$ El IV Concilio de Letrán de 1215, que generalizó el deber de anunciar la promesa en la parroquia, pretendía, al fin, proveer una solución. Pero los señores feudales rehusaron su cumplimiento. Consideraban que dada su preeminencia todos sus actos eran suficientemente conocidos. Y se hablaba de publicidad, pero no se especificaba completamente cómo debía hacerse. Las disposiciones, con todo, designaban que por matrimonio clandestino se entendía el realizado sin amonestaciones, castigándose hasta con pena de excomunión. Pero no se anulaba. A ello se sumó el desarrollo de la institución del notariado que permitió intercambiar el consentimiento ante notario y dar el matrimonio por válido. ${ }^{74}$

Prosiguieron pues las interpretaciones y matices. Algunos sínodos post-lateranenses permitiran la celebración sin sacerdote, lejos de la prescripción de Letrán, al menos para zonas rurales donde aquellos escaseaban. En la Barcelona de los siglos XIII y XIV Baucells i Reig contabilizó hasta dieciocho textos sobre el matrimonio clandestino entre constituciones provinciales, sinodales y visitas pastorales. Según este autor la Iglesia se esforzó en imponer el anuncio público, pero las familias continuaban suscribiéndolo de forma privada. ${ }^{75}$ Solo se pondría fin a las disputas a partir del decreto De clandestinis de 1563, con el que el matrimonio pasaba de ser un contrato consensual a un contrato solem-

99 Álvarez de Asturias 2013.

70 Le Bras 1926, 2220-2222; López Estévez 2004.

Sánchez-Arcilla 2010.

Aznar Gil 2006.

Esmein 1891, I: 178

Ídem, 181.

Baucells i Reig 2006, 2092, 2213. 
ne, condenando la clandestinidad a resultas de un impedimento dirimente. ${ }^{76}$

La renuencia al cambio iba a reaparecer. Una vez más, por las razones ya descritas. ${ }^{77}$ Pero también provenía de ciertos escrúpulos teológicos. Cabe indicarlos, pues podían impregnar todas las conductas. Las familias debían conocer que el matrimonio clandestino era sacramento, así se había predicado contundentemente desde el Concilio de Florencia de 1439. Y como ha escrito Luigi Nuzzo si el matrimonio era un instrumento que Cristo había dado a los hombres para permitirles obtener la gracia santificante y si para su perfeccionamiento era suficiente el libre consentimiento de los contrayentes, no parecía admisible subordinar su validez a la observancia de prescripciones vinculantes. ${ }^{78}$ Todas las culturas han afirmado el carácter sagrado del matrimonio en tanto dicha unión constituye la forma más elevada de comunión humana. La carta de san Pablo a los efesios recogía que, convertido el matrimonio en sacramento por Cristo, se rectificaban con ello los principios sacerdotales de la patria potestas romana otorgando un honor peculiar recibido por los hijos en el matrimonio cristiano, quienes deben ser respetados por sus padres y educados, sin exasperarlos en la disciplina y en la enseñanza del Señor. Esta doctrina pudo así ocasionar contrariedades. La libertad de los hijos respecto de los padres. ${ }^{79} \mathrm{Y}$ el pensamiento teológico medieval polemizaría una y otra vez acerca de si el sacramento se encontraba en el consentimiento mutuo o en su consumación. ${ }^{80}$

Demasiados recovecos donde iban a encontrar refugio los hábitos que a cada cual conviniese. Los mismos recovecos cuyas reglas no eran otras que las propias de una cultura patriarcal que sostenía que el matrimonio era un asunto de hombres, aun destinado a entrar en conflicto con los islotes de autonomía individual, las decisiones de los padres frente a las emociones de los hijos o frente a la política doméstica de las mujeres. ${ }^{81}$ El equilibrio correcto entre autoridad, obediencia y libre albedrío filial costó lograr enormes esfuerzos. Incluso tras Trento, pues aún el catecismo romano considerará el consentimiento paterno un honor legítimamente debido a quienes les dieron la vida natural. ${ }^{82}$ Un equilibrio que enlazaba con la noción de buen gobierno que se estaba entonces reflexionando en el terreno de la teoría política, lo que exhibe en suma la simbiosis entre la familia y su entorno.

\section{EL MATRIMONIO CLANDESTINO Y LA IGUALDAD DEL CONSENTIMIENTO PATERNO EN LA CASA DE GRALLA}

En el invierno de 1551 a 1552 la élite barcelonesa podía murmurar de nuevo asombrada ante un impactante suceso que tenía lugar entre sus familias. Francesc de Gralla secuestraba a sus tres hijas. El relato que ofrecemos a continuación, a fin de desarrollar la hipótesis antes apuntada, procede del estudio del desconocido e inédito expediente de la causa de restitución de dote que las hijas incoaron ante la real audiencia de Barcelona contra sendos progenitores. Nobles y caba-

$76 \quad$ Esmein 1891, II: 155; Tejero 2012.

77 Ruiz Sastre 2016, 350 y ss; Armstrong-Partida 2017.

78 Nuzzo 1998, 352; Moreno Almarcegui y Scalzo Molina 2019.

79 Tejero 2012, 455.

30 Gaudemet 1987, 146-148.

81 Duby 1991; Ago 1996

82 Usunáriz 2005, 171.
Ileros estaban acostumbrados a vivir situaciones similares. El secuestro de doncellas solía operar como un instrumento de protección, especialmente para aquellas de buena familia. En la Europa católica los conventos albergaban a estas jóvenes a fin de prepararlas en sus futuras labores maritales. Coadyuvaban así con las familias en tantos ingresos forzosos, en tantos depósitos. ${ }^{83}$ Las autoridades eclesiásticas a través de sus tribunales dictaban así mismo órdenes de secuestro para poner a salvo a mujeres en riesgo durante procesos de separación, como también a hijas díscolas. En algunos casos eran ellas mismas quienes se dirigían a esas instituciones para solicitar su propio secuestro y librarse así de un matrimonio impuesto por sus padres o tutores. ${ }^{84}$

En esta ocasión el autor era el propio padre. Francesc de Gralla también provenía de un linaje muy respetado dentro y fuera de la ciudad de Barcelona y para entonces ostentaba el cargo de maestre racional de la casa y corte, como ya lo había hecho con anterioridad su padre. ${ }^{85}$ Con todo el sigilo y premeditación, Francesc había forzado a sus tres hijas a escapar de su casa, procediendo ocultamente contra su esposa y encabezando él la huida para recluirlas en varios lugares, lejos de aquella capital en uno de cuyos más admirados palacios situado en el cruce de la calle de Portaferrissa con Cucurulla residían habitualmente. Vencidas por el debido respeto reverencial, quizás también por el miedo, cabe pensar que las jóvenes siguieron modosamente a su padre durante el secreto periplo hasta ser ocultadas en varios castillos, uno tras otro, o repartidas en unos y otros, propiedad de su padre, como el castillo de Subirats. Desconocemos el momento preciso del secuestro. $\mathrm{O}$ acaso se trataba de un rapto. En efecto, los hechos no eran ajenos a ciertos matices de violencia que caracterizaban a aquel. ${ }^{86}$ Con la diferencia que Gralla pensaría que estaba ejerciendo su derecho a la patria potestad ${ }^{87}$ y en modo alguno temería la respuesta penal atribuida al raptor. $Y$ además se añadía otra distinción: el secuestro se complacía con determinada aprobación institucional. Con todo, las constituciones catalanas, al abordar el asunto se referían al "rapto u otros actos violentos» que interviniesen en la concertación de los matrimonios. Los límites entre ambos eran difusos, compartían el ser formas de subordinación y estrategia matrimonial, tomando la definición de Danielle Haase Dubosc. ${ }^{88}$

De regreso a los hechos, no debió transcurrir escaso tiempo pues en dicho castillo les feu estar allá dos mesos. A las tres hermanas les parecería eterno, debido al displicente trato dispensado por su padre: apartadas de la conversació y star de la dita noble sa mare no podent fer ni dir sino lo que dit noble son pare manás encara que injust y contra sa llibertat. Y además, según relataba una de ellas, Jerónima, li amanassava ab grans maldissions. ${ }^{89}$ No fue poca la

Catty 1999.

44 Romance Ullod 2014, 448-450.

85 Molas 2001, 53-56.

86 Mantecón 2009.

87 Benitez 2007, 103.

88 Haase Dubosc 1999, 407-413.

89 Arxiu Nacional de Catalunya (ANC). ANC1-960-T-93. Lligall 94. «Litigio sostenido por los Exmos. Srs. cónyuges D.Luis de Requesens y Dña. Gerónima de Hostalrich contra el M. I. Sr. D. Francisco de Gralla y Desplà sobre la dote de ésta y si tuvo o no el debido consentimiento para contraer enlace...». Querela, Procés dels cónyuges Requesens sobre el dote de Gerònima, 10-V-1553, ff. 91r-92r. 
obstinación que demostró Gralla: una carta real de febrero de 1552, dirigida al gobernador de Cataluña y firmada por el regente don Felipe, insistía que conviene sacar las dichas doncellas de manos y poder del dicho mestre racional y de otra qualesquier persona o personas en cuyo poder estuvieren. La orden confiaba al alto cargo la búsqueda de las doncellas por todos los confines del Principado, recabando información entre parientes y conocidos, con la finalidad de proceder a su secuestro «legal» y depositarlas en el monasterio de Montesión de Barcelona, así como evitar que Gralla empujase a sus hijas a la clandestinidad matrimonial. Así se deduce de las palabras del regente: que no dispongays de ninguna de vuestras hijas ni las caseis sin darnos aviso. ${ }^{90}$

El comienzo de todo este trance se retrotraía al menos al año 1547, cuando en aquella familia se estaba tratando de casar a una de las hijas, Jerónima, con Luis de Requesens y Zúñiga. Los trámites eran lentos, había tiempo para llegar a acuerdos y reconsiderarlos. La información se esperaba a veces de la correspondencia de los intermediarios. Francesc de Gralla se oponía a este matrimonio. Jerónima era la primogénita, en quien pensaba para sucederle. Y tenía más donde elegir. Varios fueron los candidatos que ofrecieron su mano a estas jóvenes: moltes persones de calitat y lustre tenien ganes de casarse ab dites filles. Gralla debía valorar cada propuesta al detalle, pues des que anà perdent les esperances de haver fills de dita dona Guiomar es estat el seu proposit de casarles ab aquelles persones. Hizo planes en primer lugar con el conde de Castañeda, hijo del marqués de Aguilar, con quien incluso se había llegado a capitular ${ }^{91} y$ que era del agrado de su esposa, Guiomar de Hostalrich. Al mestre racional le iba a costar mucho librarse de la afrenta de haber dado palabra para después retirarla. ${ }^{92}$ Más tarde se planteó casarla con el conde de Aitona, que en ese tiempo acababa de suceder en los feudos del padre. Pero esta alternativa no contaba con la aquiescencia de Guiomar, por cierto, otra dama de buena familia, hija de quien fuera gobernador del Rosellón y la Cerdaña. Se trata este de un aspecto que hay que tener presente, ya que nos acerca a comprender una posición social y patrimonial en la casa de Gralla-Hostalrich muy semejante en cuanto a la procedencia de ambos cónyuges y, por lo tanto, una jefatura de aquella, en la práctica, que pudo ser compartida o que se deseaba compartir. Para que nos hagamos una idea, una estimación del valor de las joyas propiedad tanto de Francesc como de Guiomar, aportada en la causa que enfrentaría a las hermanas en 1565, mostraba un estatus muy similar. Ascendían a 2545 libras y 2450 libras respectivamente. ${ }^{93}$ Pero ese supuesto reparto de poder no iba a ser tarea fácil para la pareja. Guiomar jamás escondió su interés en disponer lo tocante a su familia: sabia molt bé lo que complia a ses filles y a sa casa segons la condicio de cada una de elles. ${ }^{94}$

90 Fargas 1997, 145-146; 2009, 172.

91 ANC1-960-T-93. Lligall 94. Demanda evocada a la Audiencia (10-V-1544), ff. 11-12r, 17-18v.

92 ANC1-960-T-93. Lligall 94. Querela. Procés dels cónyuges Requesens, ff. 22v-25r.

93 ANC1-960-T44. Lligall 45. «Documentos referentes á la Excma. Sra. Dña. Gerónima de Hostalrich y de Gralla, consorte del Excmo. Sr. D. Luis de Requesens y de Zúñiga».

94 ANC1-960-T-93. Lligall 94. Querela. Procés dels cónyuges Requesens, f. 92v.
Así pues, desesperado ante la firme oposición de Guiomar y la negativa de la joven Jerónima per tenir per cert ere de mala cristiana determinarse contra la voluntat de sa mare, ${ }^{95}$ llegaría el momento de convencer a la otra hija que quedaba, Lucrecia, quien sí acabaría cediendo a la propuesta de su padre. ${ }^{96}$ La tercera hija parece que falleció durante el trance. Al margen de una leve mención en la documentación utilizada, el silencio con que se envuelve su recuerdo hace sospechar la dureza del drama que se vivió en la familia y que se sumaba a tantas tensiones anteriores. Son pues varios los detonantes de aquel episodio y, en el núcleo de todos ellos, la disputa por la elección, pero también la disputa por quien o quienes podían decidir el destino de las hijas. Hasta entonces la vida familiar había discurrido por cauces muy prometedores: los Gralla eren opulentissims, richs de grans y oppulentissimes facultats, substancias, patrimoni de notabilissim valor y estima, així e mobles com immobles, or, argent, joyes values, castells, parroquies, vassalls emphiteutes (...) en casa de dit Francesc de Gralla ha hagut continuament caballeris, cambrers, secretari, maiordom, moltes duenyes de cambra (...) vivint reputadament y ab gran orde y fausto. A ello se sumaba que la relación entre los padres y las hijas también debió ser ejemplar pues des que nasqueren dites tres filles llegitimes y naturals son stades criades educades, instruides, erudites y ensenyades en totes bones obres, polities y gentileses ab molt gran vigilancia racatadament y ab molta honra y yndustria. ${ }^{97}$

Es probable que el secuestro de las tres hijas por Francesc de Gralla tuviera lugar de forma interpuesta a las deliberaciones matrimoniales, en medio de estas, para forzar la voluntad de las doncellas. Gralla optó por el medio más impositivo y violento, pensando concluir de forma clandestina los matrimonios de todas ellas, pues a todas a su vez las había "sustraído» de la casa familiar y del lado de su madre. Se había percatado que no podría convencerlas de otro modo y también deseaba contener el afán de mando de su esposa. Sus discrepancias con Guiomar habían dividido a la familia. Y él no aceptaba la determinación de su esposa para disponer. Debía sentir la inclinación de esta por tomar decisiones en tan elevado asunto como toda una ofensa a su jerarquía como padre en el hogar. Tras los hechos, no tardarían en vivir separados para el resto de sus vidas, confinados en los aposentos de su palacio, enfrentados en los tribunales por los alimentos prestados y por la restitución de la dote de aquella.

Durante los tratos matrimoniales se puso de manifiesto que las hijas preferían casarse contando con un consentimiento paterno procedente tanto del padre como de la madre. No podemos dejar de lado una supuesta relación entre ese consenso bilateral que tanto buscaron y la buena educación que habían recibido. Sin embargo, como ya se ha indicado, la tradición jurídica solo permitía expresamente recurrir a la madre en ausencia del padre, llamado en primer lugar: sens voluntat o consentiment pare de aquella si vivia e sil pare no del avi paternal e mare de aquella haura e si avi e mare no haura del tudor de aquella ab la vn dells sino lo tudor, ab dos o tres dels pus acostats parents de la

95 ANC1-960-T-93. Lligall 94. Ibídem, f. 91r.

96 Molas 2001, 54-55.

97 ANC1-960-T-93. Lligall 94. Memorial dels agravis pretesos per los cónyuges Requesens. 
dita donzella. Ahora bien, no tenía por impedido el consentimiento de ambos, de igual modo como se contemplaba la posibilidad de obtenerlo de dos o tres parientes a la vez en el caso de las huérfanas. ${ }^{98}$

La falta de entendimiento de los padres repercutió en la vida de las jóvenes hermanas. La conflictividad familiar desencadenó sus matrimonios, censurados o percibidos ya como clandestinos ya como ilegítimos. Nociones que, notemos, se metamorfoseaban mutuamente. Como pudo suceder en tantos otros casos. Baste recordar aquellos linajes enfrentados cuyos hijos silenciaron sus sentimientos arrojándose en manos de la fatalidad. ${ }^{99}$ La exclusión hereditaria, la patria potestad agnaticia, las jerarquías de la familia patriarcal, convivieron diariamente frente a prácticas que los retaban, los pretendían moderar o desertaban. En esas relaciones sociales y de poder el matrimonio clandestino constituía una amenaza más. El secuestro del padre venció los anhelos de las jóvenes. Así, cada una de las hermanas Gralla perdió la oportunidad de obtener una de las dos licencias. Y también cada una de ellas acabó cediendo ante un matrimonio que, para al menos uno de sus progenitores, era oculto, imperfecto, contrario a su voluntad, consideraciones todas ellas que avivaban el fantasma de la clandestinidad matrimonial. Tanto Francesc como Guiomar debieron soportar día tras día la incógnita de no saber ni cuándo ni dónde se consumaría lo que ellos juzgaban ilegítimo. Lucrecia, por ejemplo, se entregaba en matrimonio a Francesc de Montcada en alguna de tantas posesiones del conde. Su padre la recompensaba designándola heredera universal. ${ }^{100}$ Por el contrario, su madre la desheredaba sabent ella y sent molt sertificada que dita sa mare no ho volia, y la culpaba de su separación: Ans que dita dona Lucrecia fos casada (...) sempre los dits nobles mestre racional y dona Guiomar GraIla stigueren ab molta pau y concordia respectant y acatant lo hu ab lo altre com se deu entre semblants persones. La relación entre madre e hija quedó destrozada: després de son casament la ha avorrida y no la ha volguda tractar ni veure. ${ }^{101} \mathrm{Y}$ los usos de la época no facilitaban su arreglo. Lucrecia, con el favor de su padre y siendo su heredera, pasó a residir en la misma casa donde había nacido y crecido. Era habitual la convivencia entre generaciones derivada del modelo de herencia troncal. Para ambas, madre e hija, esa situación debió ser insoportable. Cada una con la pretensión de gobernar la casa, al margen de la otra. Y es que Guiomar no abandonó jamás su hogar, enferma y recluida en una ala de palacio: la dita dona Lucrecia y el dit Illustre conte de Aytona son marit son vinguts a dita casa per servir al dit don Francisco de Gralla y Despla per tenirli companyia y star a obediencia y manament (...) tots los que estan en ella siguen a ordinatio del dit son pare lo qual ha donat y dona en sa casa los aposentos y cuartos de aquella com a ella li plau (...) prengué possessió de la casa y dels bens del noble mestre racional ahont dita sa mare tenia també sos bens (...) pendré les millors istancies de la casa (...) per culpa de

98 Bermejo 2009, 141.

99 Se refiere a ello Casey 1996, 15.

100 ANC1-960-T21. Lligall 21. "Capítulos matrimoniales, procesos, inventarios, arriendos, etc.».

101 ANC1-960-T21. Lligall 21. Ibídem. Causa de restitución de dote. Documento de reclamación de legítima. Marquesa de Aitona, 1557.
Lucrecia perdé y dexá de tenir lo dit noble mestre racional lo acostumat respecte a la dita noble dona Guiomar sa muller en tant que permetia que los criats de sa casa no la servissin ni acatassen com feya abans fent-la star com una persona desemparada. ${ }^{102}$

Este relato nos describe cómo la ausencia de consentimiento matrimonial es entendida cual desafío a la jerarquía de la familia. Guiomar considera que ella ocupa ese rango en el hogar, junto a su marido. $Y$ en virtud de ello ha condenado a su hija. Muestra de la justicia doméstica que se ejercía en las familias. ${ }^{103}$ Guiomar tenía una conciencia clara de esa jerarquía y de su potestad. Mientras se estaban tratando los matrimonios alguien le había oído afirmar que no havia de fer hereva en capitols matrimonials de sos bens si no que volia tenir aquelles a totes ses voluntats per a que fos millor servida de sos gendres. ${ }^{104}$ Así pues esta condena no le permitía a Lucrecia ocupar el lugar que sí le hubiese correspondido caso de haber contraído matrimonio de la manera que no hizo. Pasados los días, los meses, la convivencia fue a peor: rompé les portes de la cambra de dita dona Guiomar o feu obrir aquelles que estaven tancades y tenia de aquelles les claus dita dona Guiomar que no ere les hores en casa y prengué una caixa ahont la dita noble dona Guiomar tenia les joyes y or y sen portà aquella en lo apposento on estava la dita dona Lucrecia que ha consentit volentse ser señora de les joyes y or de sa mare vivint aquella. ${ }^{105}$ Esta violencia consumaba el desorden en que se había sumido la casa. Y constituía otra de las graves consecuencias a que se llegaba con este tipo de matrimonio clandestino, desprovisto de una parte esencial del consentimiento al que sin éxito se había apelado - en tiempos distintos - dentro de la familia, ya fuera por obediencia ya por autoridad. La legislación ubicaba el papel de la madre en segundo término. Las alegaciones de Lucrecia para desmontar los argumentos que justificaban su desheredamiento abordaban esta cuestión: los fills y filles en sos actes et en cars de matrymoni son més obligats a la obedientia del pare que de la mare així per disposició de dret civil com canonic (...) de dret civil y canonic lo pare te més potestat y domini sobre los fills legitims y naturals que no la mare (...) la ley comuna en lo casament de les filles vol y entrevingue consentiment del pare si viura y no vivint aquell de l'avi paternal si viura y en defalliment del pare y avi paternal demane lo consentiment de la mare (...) la dita Lucrecia no ere obligada de obeir a sa mare(...). ${ }^{106}$ La cultura patriarcal imponía distintas intensidades de obediencia, entre padres o madres. Si alguien osaba ponerlas en duda provocaba un conflicto. $Y$ en este caso esa fue Guiomar. Cabe pensar que en la mayor parte de la cotidianeidad semejante diferencia podría ser negociada. Por alguna razón la pareja Gralla-Hostalrich no accedió a ello: mai hagué conformitat entre los pares. Pese a los ruegos de

102 ANC1-960-T21. Lligall 21. Causa de restitución de dote. Documento de reclamación de legítima. Marquesa de Aitona, 1557.

103 Rodríguez Sánchez 1990.

104 ANC1-960-T-93. Lligall 94. Demanda evocada a la reial audiencia, f. 8.

105 ANC1-960-T-92. Lligall 93. «Pleito habido entre las M. Iltres. familias de Gralla y Hostalrich sobre el cobro de la dote que en fuerza de sus capítulos matrimoniales debía percibir la M. I. Sra. Dña. Guiomar de Hostalrich». Qüestiones, dudas.

106 ANC1-960-T-93. Lligall 94. Querela. Procés dels cónyuges Requesens, f. 72 
Jerónima, la primogénita, que había escrito cartas durante el encierro enviades secretament a sa mare supplicant-la se volgués accedir en lo que son pare volia (...) ella sabia molt de quant era la ira de sa mare y que mai la perdonaria y que aixi determinaria de sposarse abans en un monestir (...). ${ }^{107}$ Fracasado su secuestro, y en lo que atañía a Jerónima, su padre no volia consentir ni tampoc expressament dissentir. ${ }^{108} \mathrm{Y}$ la imprecisión, cuando no la exclusión por parte de la norma de un consentimiento simultáneo, de padre y madre, fue contraproducente en esta historia.

Y así, pasada la medianoche de una jornada de primavera de 1552 y junto a las puertas de su casa, Jerónima se prometía. Contaba solo con el apoyo explícito de su madre. Mientras, su padre permanecía encerrado arriba, en su cámara, sin atender súplicas de nadie y habiéndola ya desheredado porque per ninguna via dita dona Hyeronima se volia apiadar de la honra y treballs de son pare tingué a bé de no curar més de la collocatio de dita sa filla (...) ella mai volgué escriure al dit son pare. ${ }^{109}$ Sus alegaciones en el posterior pleito dejan caer la duda no obstante de un posible consentimiento tácito de su padre. Una vez más las grietas de la norma, la pugna por los efectos jurídicos de aquel. De hecho algún testigo de la causa había afirmado que nunca havia vist més alegre al sr mestre racional que en la hora que es fes lo casament del illustre comanador maior (...) havia fet oració expressament per dit casament. ${ }^{110}$ Pero su actitud pasiva lo contradecía. Parece que la joven se casó, pocos días más tarde, en la catedral de Barcelona, en una misa oficiada por el obispo. Se habían firmado las capitulaciones matrimoniales en el monasterio del Carme. La pérdida del favor del padre obligaba a alojar los secretos acuerdos lejos de la casa familiar, ahora quebrada su paz. Tras el ritual canónico la boda se festejó en una casa propiedad de su madre, situada en la barcelonesa calle de Mercaders. Era toda una provocación para su padre. Pero Jerónima siempre había alegado que era la obediencia caritativa la que le había llevado a seguir el consejo de su madre tras haberla escuchado confesar que le paria que seria cosa util per a sa filla y gran consol per a la sua poca vida que llavors tenia a causa de les tant sobrades malalties que la tenien deprimida (...) la vida de dona Guiomar seria poca, que lo mestre racional se casaria y que publicament servia ja a una dama (...) li porfia del mestre racional la havia de acabar de matar. ${ }^{111}$

Varios litigios abonaron el cruce de sospechas, reproches. Un sombrío ambiente iba a presidir el día a día en la casa de Gralla-Hostalrich durante muchos años. Entre el padre, la madre mientras aún viviese y sus hijas. También entre las propias hermanas. El desheredamiento y la pérdida de la dote desplegaron causas muy prolongadas y dolorosas. Y en lo más profundo de las vidas de aquellas jóvenes damas, habitaba el recuerdo de no haber podido hacer y

107 ANC1-960-T-93. Lligall 94. Ibídem, f. 92.

108 ANC1-960-T-93. Lligall 94. Summari de les paraules essencials dels testimonis del mestre racional, ff. 2-8r.

109 ANC1-960-T-93. Lligall 94. Demanda evocada a la Audiencia (10-V-1544), f. 17r.

110 ANC1-960-T-93. Lligall 94. Memorial dels agravis pretesos per los cónyuges Requesens, f. 5

111 ANC1-960-T-93. Lligall 94. Querela. Procés dels cónyuges Requesens, f. 105-106. ANC1-960-T-93. Lligall 94. Demanda evocada a la Audiencia, f. 18-19r. celebrar su matrimonio como cabía esperar del estatus en el que se habían criado.

\section{CONCLUSIONES}

Son varios los elementos que explican el problema que protagoniza el presente estudio. Tanto las jerarquías familiares, como la regulación y grietas normativas del consentimiento paterno o la relegación en este de la madre, lo que no todas las mujeres encajarían dócilmente, fueron detonante de las vivencias que se narran en esta historia de clandestinidad. De la suma de aquellos se infiere una competencia por el poder doméstico. Y por el poder de los linajes, habida cuenta que concertar matrimonios constituía un negocio con el que la red de parientes se reposicionaba cada vez que esto ocurría en su espacio social. Pero el alcance del conflicto también resultó de la existencia de unas condiciones que fueron óptimas para el uso y abuso de dichos elementos. Entre estas hay que notar, los delgados márgenes entre obediencia razonable y sumisión con las que se relacionaban padres e hijos o incluso más intensamente padres e hijas. A su lado, la práctica tan instalada del secuestro autorizado, como también la compleja noción de matrimonio solo consenso que de modo tan confuso había llegado a las familias. Aunque a estas también les pudiera venir bien dicha confusión. No es improbable que, con el secuestro de sus hijas, Gralla pretendiese simular que las apartaba de su intransigente madre e indómita esposa, para que ellas decidiesen fuera de su influencia y llegasen a prestar su consentimiento con toda libertad. Su puesta en escena, a la vista externa, mezclaba un ansia por demostrar quien mandaba revestida de un mensaje moral de buen padre y prudente jefe de familia. Las maniobras y los juegos del poder conyugal disfrazados de apariencias y emociones encontradas condicionaban los resultados de cada operación. Sin dejar de lado la obvia disputa de género en el ámbito del modelo patriarcal. Esta microhistoria lo explica muy bien. Existió una contienda por la coparticipación en la toma de decisiones trascendentes, sociales y políticas, en aquella familia. Pero para Francesc debía ser humillante ceder parte del monopolio naturalmente atribuido al varón. Y Guiomar hacía valer sin duda su categoría familiar. Acaso también entendía esa desconsideración a la jurisdicción de su esposo, como un merecido castigo por su falta de lealtad. Debemos articular entre sí todo este conjunto de variables para entender cómo se producía o se llegaba al matrimonio clandestino. Este formaba parte de la vida cotidiana, de las convicciones morales. Los conflictos familiares, también. Y aquellos derivados de la competencia patrimonial o por la posición social subyacente a la patrimonial, entre las élites, mucho más. En el caso estudiado, la preexistencia de un conflicto de poder doméstico conllevó en las hijas al fraccionamiento del consentimiento paterno con actos consiguientes de clandestinidad matrimonial y de sombra de ilegitimidad.

\section{BiBLIOGRAFÍA}

Ago, Renata. 1996. "Jóvenes nobles en la época del absolutismo: autoritarismo paterno y libertad». En Historia de los jóvenes, edición de Giovanni Lévi y Carl Schmitt, I, 365-413. Madrid: Taurus. 
Álvarez de Asturias, Nicolás. 2013. «La formación del vínculo matrimonial de Graciano a Alejandro III: ¿tan solo una cuestión histórica?». lus canonicum 53: 621-654.

Ariès, Philippe. 1988. El niño y la vida familiar en el antiguo régimen. Madrid: Taurus.

Armstrong-Partida, Michelle. 2017. «Concubinage, clandestine marriage, and gender in the visitation records of fourteenth-century $\mathrm{Ca}$ talonia». Journal of the history of sexuality 26 (2): 207-238. http:// www.jstor.org/stable/44862382

Armstrong-Partida, Michelle. 2017. Defiant priests: domestic unions, violence, and clerical masculinity in fourteenth-century Catalunya. Ithaca, New York: Cornell University Press.

Ayllón, Emilio. 1862. Examen histórico crítico-filosófico de la doctrina del consentimiento paterno para la celebración del matrimonio. Cádiz: Imprenta de la revista médica.

Aznar Gil, Federico. 1995. «El consentimiento paterno o familiar para el matrimonio en la legislación eclesiástica ibérica bajomedieval (s. XII-XVI)». Rivista internazionale di diritto comune 6: 127-151.

Aznar Gil, Federico. 2006. "Penas y sanciones contra los matrimonios clandestinos en la península ibérica». Anales de la facultad de teología 57 (1): 343-369.

Baucells i Reig, Josep. 2006. Vivir en la edad media. Barcelona y su entorno (siglos XIII y XIV). III. Barcelona: CSIC

Benítez, Laura. 2007. "El rapto, un repaso histórico-legal». Estudios sociales 1: 103-131.

Bermejo Castrillo, Manuel Ángel. 2009. Entre ordenamientos y códigos. Legislación y doctrina sobre la familia a partir de las leyes de Toro. Madrid: Dyckinson.

Blanco Carrasco, José Pablo. 2016. «Disensos. Conflictos de la patria potestad en la España rural moderna». Studia Histórica: Historia Moderna 38 (2): 107-135. https://doi.org/10.14201/ shhmo2016382107135

Bonfield, Lloyd. 2002. «Avances en la legislación familiar europea». En La vida familiar a principios de la era moderna (1500-1789), ed. David I. Kertzer y Marzio Barbagli, 153-203. Barcelona: Paidós.

Byars, Jana. 2018. Informal marriages in early modern Venice. Routledge research in gender and history, 33. London: Routledge.

Candau, María Luisa. 2006. «El matrimonio clandestino en el siglo XVII: entre el amor, las conveniencias y el discurso tridentino». Estudios de Historia de España VIII: 189-200.

Candau, María Luisa. 2008. «El matrimonio presunto, los amores torpes y el incumplimiento de la palabra: archidiócesis de Sevilla, siglos XVII y XVIII». En Padres e hijos en España y el mundo hispánico: siglos XVI y XVIII, ed. Jesús M. a Usunáriz y Rocío García Bourrellier, 35-51. Madrid: Visor.

Candau, María Luisa, ed. 2014. Las mujeres y el honor en la Europa moderna. Huelva: Universidad de Huelva.

Casey, James. 1990. Historia de la familia. Madrid: Espasa-Calpe.

Casey, James. 1996. "La conflictividad en el seno de la familia». Estudis: Revista de historia moderna 22: 9-26.

Casey, James. 2008. "El matrimonio clandestino en Andalucía en la época moderna». En Familia y sociedad en el reino de Granada durante el antiguo régimen, ed. James Casey, 15-35. Granada: Universidad de Granada.

Catty, Jocelyn. 1999. Writing rape, writing women in early modern England: unbridled speech. Basingstoke: Macmillan.

Charageatu, Martine. 2014. «Sage polyvalent et evolution du concept de rapt en aragon : entre normes et recits judiciaires (XIII $-\mathrm{XIX}^{\mathrm{e}}$ siècles)». Estudis. Revista de Historia Moderna 40: 13-30.

Christensen-Nugues, Charlotte. 2014. "Parental authority and freedom of choice: the debate on clandestinity and parental consent at the Council of Trent». Sixteenth century journal XLV, 1: 51-72.

Costa, Marie. 2007. Conflictos matrimoniales y divorcio en Cataluña: 1775-1833. Tesis doctoral. Universitat Pompeu Fabra.

Cristellón, Cecilia. 2005. «El matrimonio antes del Concilio de Trento en la República de Venecia». En El matrimonio en Europa y el mundo hispánico, ed. Ignacio Arellano y Jesús M. Usunáriz, 179-180. Madrid: Visor libros.

D’Avray Papacy, David. 2015. Monarchy and marriage, 860-1600. Cambridge: Cambridge University Press.

Diefendorf, Barbara. 1996. "Give us back our children: patriarchal authority and parental consent to religious vocation in early counterreformation France». The Journal of modern history 68: 265-307.
Dillard, Heath. 1993. La mujer en la Reconquista. Madrid: Nerea.

Donahue, Charles Jr. 2007. Law, marriage and society in the later middle ages: arguments about marriage in five courts. Cambridge: Cambridge University Press.

Duby, Georges. 1991. «Poder privado, poder público». En Historia de la vida privada ed. Georges Duby y Phillippe Ariès, II, 53-158. Madrid: Taurus.

Duby, Georges. 1985. El caballero, la mujer y el cura: el matrimonio en la Francia feudal. Madrid: Taurus.

Dunn, Caroline. 2013. Stolen women in medieval England. Rape, abduction and adultery 1100-1500. Cambridge: Cambridge University Press.

Dyer, Abigail. 2003. "Seduction by promise of marriage: law, sex, and culture in seventeenth-century Spain». The sixteenth century journal 34 (2): 439-455.

Esmein, Adhémar. 1891. Le mariage en droit canonique. Paris: Larose et Forcel.

Fargas Peñarrocha, Mariela. 1997. Família i poder a Catalunya, 15161621. Les estratègies de consolidació de la classe dirigent. Barcelona: Fundació Noguera.

Fargas Peñarrocha, Mariela. 2009. «Nupcias y movilidad social en la constitución de lo público y lo privado en la Barcelona moderna». Cuadernos de historia moderna. Anejos 8: 151-173.

Finch, Andrew. 1990. "Parental authority and the problem of clandestine marriage in the later middle ages». Law and history review 8(2): 189-204.

Finch, John. 1990. «Parental authority and the problem of plandestine marriage in the later middle ages». Law and history review 8(2): 189-204.

Flandrin, Jean Louis. 1984. Familles, parenté, maison, sexualité dans I'ancienne socété. Paris: Éditions du Seuil.

García González, Juan. 1953. «El incumplimiento de las promesas de matrimonio en la historia del derecho español». Anuario de historia del derecho español 23: 611-642.

Gascón Uceda, Isabel. 2013. «Entre el deseo y la realidad. Mujer y matrimonio en la edad moderna». En Historia(s) de mujeres, coord. Pilar Pezzi, II, 153-171. Málaga: Universidad de Málaga.

Gaudemet, Jean. 1987. Le mariage en occident. Les moeurs et le droit. París: Le Cerf.

Gibert, Rafael. 1947. «El consentimiento familiar en el matrimonio según el derecho medieval español». Anuario de Historia del Derecho Español 18: 706-761.

Goody, Jack. 1986. La evolución de la familia y del matrimonio en Europa. Barcelona: Herder.

Haase Dubosc, Danielle. 1999. Ravie et enlevée. De l'enlèvement des femmes comme stratégie matrimoniale au XVIlè siècle. Paris: Albin Michel.

Hacke, Daniela. 2001. "Non lo volevo per marito in modo alcuno': forced marriages, generational conflicts, and the limits of patriarchal power in early modern venice, c. 1580-1680». En Time, space, \& women's lives in early modern Europe, ed. Anne Jacobson Schutte, Thomas Kuehn y Silvana Seidel Menchi, 205-217. Kirksville: Truman State University Press.

Hanley, Sarah. 2003. "The jurisprudence of the arrets: marital union, civil society, and state formation in France, 1550-1650». Law and history review 21: 1-40. https://doi.org/10.2307/3595067

Iglesia Ferreirós, Aquilino. 1974. «Uniones matrimoniales y afines en el derecho histórico español». Revista de derecho notarial 85-86: 71-107.

Joyce, Georges. 1948. Christian marriage: an historical and doctrinal study. Londres: Sheedand ward.

Kamen, Henry. 1998. Canvi cultural a la societat del segle d'or. Lleida: pagès.

Korpiola, Mia, ed. 2011. Regional variations in matrimonial law and custom in Europe, 1150-1600. London: Brill.

Laina Gallego, José María. 1992. Libertad y consentimiento paterno para el matrimonio en la legislación española. Tesis doctoral. Universidad Complutense de Madrid.

Le Bras, Georges. 1926. "La doctrine du mariage chez les théologiens et les canonistes depuis l'an mille». Dictionnaire de théologie catholique, VI, cols. 2220-2222. París: Letouzey et Ané . 
López Estévez, Jonathan. 2004. "La potestad de establecer los impedimentos matrimoniales en el tratado "de sponsalibus et matrimoniis" de lohannes Brunellus». Ius canonicum 44 (87): 113-140.

López Medina, Aurora. 2013. "Consecuencias socio-jurídicas de la regulación del rapto en materia matrimonial». Revista general de derecho canónico y derecho eclesiástico del estado 31.

Lorenzo Pinar, Francisco J. 2013. "Actitudes violentas en torno a la formación y disolución del matrimonio en castilla durante la edad moderna». En Furor et rabies: violencia, conflicto y marginación en la edad moderna, 159-163. Santander: Universidad de Cantabria.

Mantecón Novellán, Tomás. 2009. «Hogares infernales: una visión retrospectiva sobre la violencia en el mundo moderno». En La familia en la historia, coord. Francisco José Lorenzo Pinar, 187-230. Salamanca: Ediciones Universidad de Salamanca.

Maspons, Francesc. 1952. Fons de dret català. Barcelona: Rafel Dalmau.

Mazo Karras, Ruth. 2012. Unmarriages: women, men, and sexual unions in the middle ages. Philadelphia: University of Pennsylvania Press.

Molas, Pere. 2001. «Dames del Renaixement». Pedralbes. Revista d'Història Moderna 21: 45-64.

Morales y Alonso, Juan P. 1895. Instituciones de derecho canónico. Madrid: Imp. J. Góngora Álvarez.

Moreno Almárcegui, Antonio y Germán Scalzo Molina. 2019. Entre don y contrato. Una historia de la comprensión del matrimonio. Pamplona: EUNSA.

Newton, Gill. 2014. "Clandestine marriage in early modern London: when, where and why?». Continuity and change 29 (2): 151-180.

Nuzzo, Luigi. 1998. "Il matrimonio clandestino nella dottrina canonistica del basso medioevo». Studia et documenta historiae et iuris 64: 351-396.

Orlandis Rovira, José. 1944. "La paz de la casa en el Derecho español de la alta edad media». Anuario de historia del derecho español 15: 107-161.

Outhwaite, Robert B. 1995. Clandestine marriage in England, 15001850. London: The Hambledon Press.

Ozment, Stephen. 1988. When fathers ruled: family life in reformation Europe. Cambridge - Massachussets: Harvard University Press.

Pérez Molina, Isabel. 1997. Las mujeres ante la ley en la Cataluña moderna. Granada: Universidad de Granada.

Peters, Christine. 2000. «Gender, sacrament and ritual: the making and meaning of marriage in late medieval and early modern England». Past \& present 169: 63-96. https://doi.org/10.1093/past/169.1.63

Quesada Morillas, Yolanda. 2018. El delito de rapto en la Historia del Derecho castellano. Madrid: Dikynson.

Rey, Ofelia. 2019. «Normes et pratiques de la cérémonie du mariage dans le nord de l'Espagne avant le concile de Trente». Bulletin de correspondance hellénique moderne et contemporain 1. https:// doi.org/10.4000/bchmc. 292

Rodríguez-Arango, Crisanto. 1952. «El matrimonio clandestino en la novela cervantina». Anuario de historia del derecho español XXV: 731-774.

Rodríguez Sánchez, Ángel. 1990. «El poder familiar: la patria potestad en el Antiguo Régimen». Chronica Nova 18: 365-380.
Romance Ullod, Joan. 2014. «Secuestros de doncellas. El control jurisdiccional del matrimonio en el obispado de Barcelona de 1600 a 1700». Pedralbes. Revista d'Història Moderna 34: 445-455.

Roper, Lyndal. 1985. "Going to Church and Street: Weddings in Reformation Augsburg». Past and Present 106: 62-101.

Ruiz Sastre, Marta. 2014. "Vidas unidas contra el discurso tridentino: el matrimonio clandestino en la Sevilla del seiscientos». En Las mujeres y el honor en la Europa moderna, ed. María Luisa Candau, 245. Huelva: Universidad de Huelva.

Ruiz Sastre, Marta. 2016. Mujeres y conflictos en los matrimonios de Andalucía occidental: el arzobispado de Sevilla durante el siglo XVII. Tesis doctoral. Universidad de Huelva.

Ruiz Sastre, Marta y María Luisa Candau. 2016. «El noviazgo en la España moderna y la importancia de la «palabra». Stvdia histórica. Historia moderna 38 (2): 55-105. https://doi.org/10.14201/ shhmo201638255105

Sánchez-Arcilla Bernal, José. 2010. «La formación del vínculo y los matrimonios clandestinos en la baja edad media». Cuadernos de historia del derecho 17: 7-25.

Seidel Menchi, Silvana y Diego Quaglioni, eds. 2001. Matrimoni in dubbio: unioni controverse e nozze clandestine in Italia dal XIV al XVIII secolo. Bologna: II mulino.

Sperling, Jutta. 2004. «Marriage at the time of the Council of Trent (1560-70): clandestine marriages, kinship prohibitions, and dowry exchange in European comparison». Journal of Early Modern History 8, 67-108. https://doi.org/10.1163/1570065041268951

Stone, Lawrence. 1990. Familia, sexo y matrimonio en Inglaterra, 1500-1800. México: Fondo de Cultura Económica.

Tejero, Eloy. 2012. «La secularización inicial del matrimonio y de la familia en la doctrina del siglo XVI y su incorrecta comprensión de la antigüedad». Ius canonicum 52: 425-464.

Telle, Emille. 1954. Erasme de Rotterdam et le septième sacrement: étude d'évangelisme matrimonial au XVI'̀ siècle et contribution à la biographie intellectuelle d'Erasme. Génève: Droz.

Torremocha Hernández, Margarita. 2016. «Solteria, mujer y litigiosidad en el cotidiano de la Edad Moderna. A vueltas con las palabras de matrimonio». Revista Portuguesa de Historia XLVII: 153-174.

Usunáriz, Jesús M.a 2005. «El matrimonio como ejercicio de libertad en la España del siglo de oro». En El matrimonio en Europa y el mundo hispánico, ed. Ignacio Arellano y Jesús M.a Usunáriz, 169175. Madrid: Visor libros.

Vial-Dumas, Manuel. 2015. «Notas sobre el matrimonio en el oriente y el occidente cristiano durante la Antigüedad tardía y el alto medioevo». lus fugit 18: 141-165.

Wall, Alison. 1995. "For love, money, or politics? a clandestine marriage and the Elizabethan court of Arches». The historical journal 38 (3): 511-533.

Watt, Jeffrey R. 2004. «El impacto de la Reforma y la Contrarreforma». En Historia de la familia europea, comps. Marzio Barbagli y David Kertzer, 205-248. Barcelona: Paidós ibérica.

Weigand, Rudolf. 1990. «Desarrollo y triunfo del principio del consentimiento en el derecho matrimonial de la iglesia». Revista Española de Derecho Canónico 47: 53-67. 